\title{
JCEIB
}

Journal Chemical Engineering and Industrial Biotechnology (JCEIB)

Open Access

Volume 1 pp. 13-26; September 2017

CUniversiti Malaysia Pahang Publisher

DOI: https://doi.org/10.15282/JCEIB-V1-17.29/9/2017/2.2

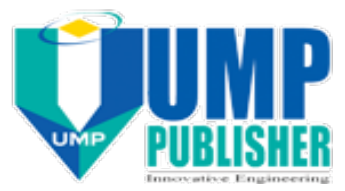

\section{ADSORPTION AND KINETIC STUDIES OF A NATURAL DYE FROM CURCUMA LONGA L., ONTO BAMBOO YARN}

\author{
Tengku Khamanur Azma Tg. Mohd Zamri, Mimi Sakinah Abd Munaim", Zularisam Ab \\ Wahid \\ Department of Engineering technology, Faculty of Engineering Technology, Universiti Malaysia \\ Pahang, 26300 Gambang, Kuantan Pahang Darul Makmur, Malaysia \\ * Corresponding author:mimi@ump.edu.my
}

\begin{abstract}
Natural dye extracted from the rhizome of Curcuma longa L. were applied to bamboo yarns using exhaustion dyeing process. This study investigates the dyeing behaviour of Curcumin; the major color component isolated from rhizomes of Curcuma longa L.on bamboo yarn. Langmuir, Freundlich, Tempkin and Dubinin-Radushkevich isotherm models were used to test the adsorption process of curcumin on bamboo yarn. Comparison of regression coefficient value indicated that the Freundlich isotherm most fitted to the adsorption of curcumin onto bamboo yarn. Furthermore, the kinetics study on this research fitted the pseudo-second order model which indicates that the basis of interaction was chemical adsorption.
\end{abstract}

Keywords: Natural dye; Curcuma longa L.,; Adsorption; Kinetics; Bamboo yarn; Dyeing

\subsection{INTRODUCTION}

Dyeing of nylon, wool, silk, leather, and cotton in textile industries often use extensive synthetic dyes (Sinha et al., 2012). Research has shown that most of the synthetic dyes are toxic (Selvam et al., 2015), carcinogenic (Haddar et al., 2014) causes harmful effects (Sinha et al., 2012) and are a major source of environmental pollution (Khan et al., 2014). For this reasons, the interest for natural dye application in textile coloration has revived as they are (Shams-Nateri, 2011) non-toxic (Boonsong et al., 2012), ecofriendly (Khan et al., 2014) and biodegradable (Nasirizadeh et al., 2012). The use of natural dyes can significantly minimize the volume of toxic effluent resulting from the conventional dyeing process (Haddar et al., 2014). Consequently, extensive investigation on the extraction of colourants from different plant parts has been done by researchers. Curcuma longa L. (Figure 1) is a perennial plant from the ginger family (Zingiberaceae). It is used in India and East Asia since antiquity as a dye, medicine and flavouring agent, seasoning and preservative (Sathiyabama et al., 2016). Recently, it is utilized fundamentally as a characteristic shading specialist to supplant manufactured colours (Osorio-Tobón et al., 2014). The shade of turmeric is credited for the most part to a gathering of phenolic mixes named curcuminoids (Osorio-Tobón et al., 2014). $C$. longa, also known as haldi, curcumin and turmeric. In turmeric rhizomes, there are three main curcuminoids which are known as curcumin, demethoxycurcumin, and bisdemethoxycurcumin as shown in Figure 2 (Osorio-Tobón et al., 2016). Curcumin, the main active constituent in $C$. longa displays a range of biologically important 
properties such as antioxidant, anti-inflammatory, antimutagenic, anticarcinogenic and antiangiogenic (Anusuya and Sathiyabama, 2016). Curcumin is the pigment which imparts yellow colour on textile fibres (Sachan and Kapoor, 2007). Literature is abundant with reports pertaining the application of natural dye extracted from C. longa and the evaluation of their dyeing properties on various fibers (Selvam et al., 2015; Boonsong et al., 2012; Sachan and Kapoor, 2007; Zhou et al., 2015; Kulkarni and Bodake, 2011; B and Ravi, 2013). However, reports on their kinetic and adsorption aspects are limited. The lack of resources and interest on this aspect lead to the establishment of this study, which focused on evaluating the dyeing properties, and adsorption of natural dye extracted from the rhizomes of $C$. longa onto bamboo yarn. Bamboo has developed as an extreme green material meeting the meaning of an in exhaustible and feasible crude material with minimal destructive effect to nature (Tausif et al., 2015). Regular bamboo fibres have superb properties and hence the potential for use in materials (Prakash et al., 2012). Following were the objectives of this research. 1) To extract the main colour component from the rhizomes of $C$ longa 2) To explore the dyeing properties of the colour component on bamboo yarn, 3) To study adsorption isotherms of the colour component on bamboo yarn and 4) To evaluate the dyeing process through kinetic studies.

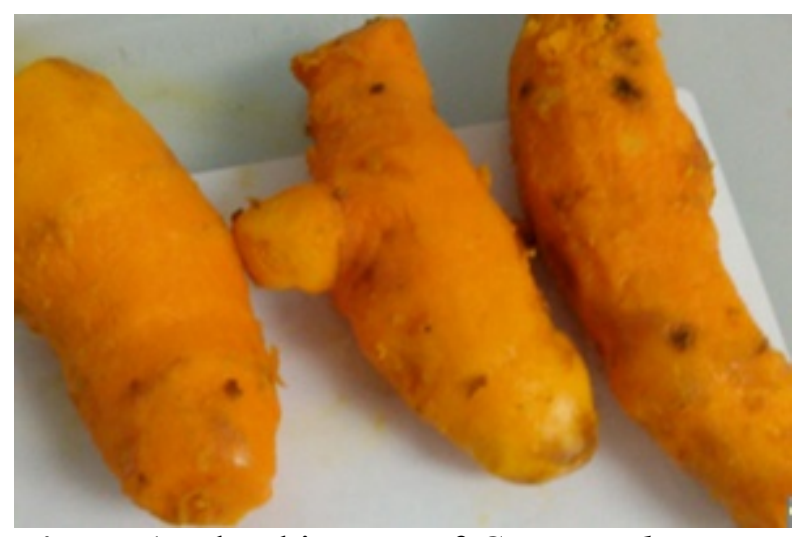

Figure 1: The rhizomes of Curcuma longa L., 
<smiles>O=C(/C=C/c1ccc(O)cc1)CC(O)/C=C/c1ccc(O)cc1</smiles><smiles>COc1cc(/C=C/C(=O)CC(=O)/C=C/c2ccc(O)c(OC)c2)ccc1O</smiles>

Figure 2: Structure of the three main curcuminoids found in rhizomes of Curcuma longa L.,(Osorio-Tobón et al., 2016)

\section{Plants material}

\subsection{MATERIALS AND METHODS}

The experiment was performed using rhizome of $C$. longa and obtained from a mall in Taman Tas, Kuantan, Pahang. The raw material was peeled and blended into small pieces. Storage of blended turmeric at $-20^{\circ} \mathrm{C}$ for not more than two days ( 48 hours) helped maintain freshness and avoided color fading due to the oxidation process.

\section{Fibre Material}

Pusat Tenun Pekan, Pahang provided the bamboo yarns, which are of $100 \%$ bamboo fibers. shows the chemical structure of cellulose bamboo fibre.<smiles>CC[C@@]1(C)OC(CO)C2OC(OC(CO)C3O[C@](C)(CC)C(O)C3O)C(O1)C2O</smiles>

Figure 3: Chemical Structure of Cellulose in Bamboo Fibre (Chen, 2014)

\section{Chemical and Reagents}

Both sodium hydroxide and chloric acid used are of analytical reagent grade. Meanwhile, purchase of curcumin standard was from Sigma-Aldrich. 


\section{Dye Extraction}

Cleaned and peeled rhizomes of C. longa were further blended into small pieces, about $1 \mathrm{~mm}$ in size, to increase the surface area. Next, the extraction of natural yellow dye used a ratio $0.12 \mathrm{~g} / \mathrm{mL}$ corresponding to the ratio of $1.2 \mathrm{~g}$ of raw material to $10 \mathrm{~mL}$ of distilled water. The mixture was centrifuged at $4^{\circ} \mathrm{C}, 10000 \mathrm{rpm}$ for 15 minutes (Anusuya and Sathiyabama, 2016) and filtered to collect the supernatant dye. Recentrifuged of the supernatant at $4{ }^{\circ} \mathrm{C}, 12000 \mathrm{rpm}$ for 10 minutes (Sachan and Kapoor, 2007) ensured that no sediment or precipitate was present in the dye solution. Finally, the supernatant was filtered using a stainless filter paper, and $\mathrm{pH}$ was adjusted with $\mathrm{HCl}$ and $\mathrm{NaOH}$ if needed. The following experiment was performed using the extracts developed.

\section{Dyeing Procedure}

The absorbance of the prepared yellow dye solution was measured and recorded using a UV-Vis Spectrophotometer. Next, the bamboo yarn was dyed at a weight ratio of 1:100 bamboo yarn in the yellow dye solution. The bamboo yarn in yellow dye solution was agitated in an incubator shaker (KS4000i) at about $100 \mathrm{rpm}$ in room temperature. Reading of dye solution were taken after the sample was left 30 minutes at $\mathrm{pH} 6.5$. The $\mathrm{pH}$ was adjusted with $\mathrm{HCl}$ and $\mathrm{NaOH}$ if needed.The dyed bamboo yarn was then dried and soaked in a $25 \%$ aluminium sulphate (Alum) solution, which acts as a mordant. The mordant solution was heated up to $70{ }^{\circ} \mathrm{C}$ and then left to cool for 45 minutes. The bamboo yarn was then removed from the mordant solution and rinsed well with distilled water.

\section{Calculations of curcumin pigments}

The curcumin content was estimated as per the method using standard calibration curve. Measurements of the intensity of the yellow colour of both extract and standard at 425 $\mathrm{nm}$ were taken in a spectrophotometer (Hmar et al., 2016), and the following equation was used to calculate curcumin content:

$$
\text { Total Curcumin Content }\left(\frac{m g}{L}\right)=\frac{A(M W) V(D F)}{\varepsilon L} \times 1000
$$

Where, $A$ is the value of absorption at the maximum absorbance $(\chi=425 \mathrm{~nm}), M W$ is the molecular weight of curcumin $(368.38 \mathrm{~g} / \mathrm{mol}), L$ is cell length in $\mathrm{cm}, D F$ is dilution factor and $\varepsilon$ is the mean molar mean molar absorptivity $(23800 \mathrm{~L} / \mathrm{mol} \mathrm{cm})$. The difference in curcumin content $(\mathrm{CC})$ can be determined using the following formula:

$$
\text { CC }(\text { before })-C C(\text { after })=C C \text { on bamboo yarn }
$$

\section{Adsorption Procedure}

Different concentrations of dye solution were prepared using different dilution factors of the dye. Table 1 shows the dilution factors used, which are 1.07, 1.15, 1.25, 1.36 and 1.50. This analysis used distilled water as a blank solution. The dye solution was added into a cuvette and placed into the spectrophotometer for optical density measurement. The wavelength for dye from $C$. longa rhizomes was at $425 \mathrm{~nm}$. The study recorded the optical densities for each dye concentration. Next, $0.2 \mathrm{~g}$ of bamboo yarn were left to soak in several $20 \mathrm{ml}$ test tubes containing dye solution of different concentrations. They are left for 90 minutes as it is the equilibrium time for dye solution and another 24 hours for the drying process. The optical density of remaining dye solution in the test tube after fabric removal were measured. After obtaining the optical density readings 
for both before and after adsorption process, the values were introduced to the equation to calculate the total curcumin content in the rhizomes of $C$. longa dye that was adsorbed by the bamboo yarn. The amount of dye adsorbed per unit for the weight of bamboo yarn at equilibrium $\mathrm{q}_{\mathrm{e}}(\mathrm{mg} / \mathrm{g}$ bamboo yarn) was calculated using equation (4), where $\mathrm{C}_{0}$ is the initial dye concentration $(\mathrm{mg} / \mathrm{L})$ in the solution. $\mathrm{C}_{\mathrm{e}}$ is the unbound dye concentration $(\mathrm{mg} / \mathrm{L})$ at equilibrium. $\mathrm{V}$ is the initial volume $(\mathrm{L})$ of the dye solution, $\mathrm{m}$ is the dry adsorbent dosage $(\mathrm{g})$, and $\mathrm{W}$ is the weight of bamboo yarn (g) (Sivakumar et al., 2009; Bu et al., 2016).

$$
q_{e}=\frac{\left(C_{0}-C_{e}\right) V}{W}
$$

Table 1: Water and Dye Ratio for Dilution Factor

\begin{tabular}{ccc}
\hline Dilution Factor & Water $(\mathrm{mL})$ & Dye $(\mathrm{mL})$ \\
\hline 1.07 & 2 & 28 \\
1.15 & 4 & 26 \\
1.25 & 6 & 24 \\
1.36 & 8 & 22 \\
1.50 & 10 & 20 \\
\hline
\end{tabular}

\subsection{RESULTS AND DISCUSSIONS}

\section{Effect of time on adsorption equilibrium}

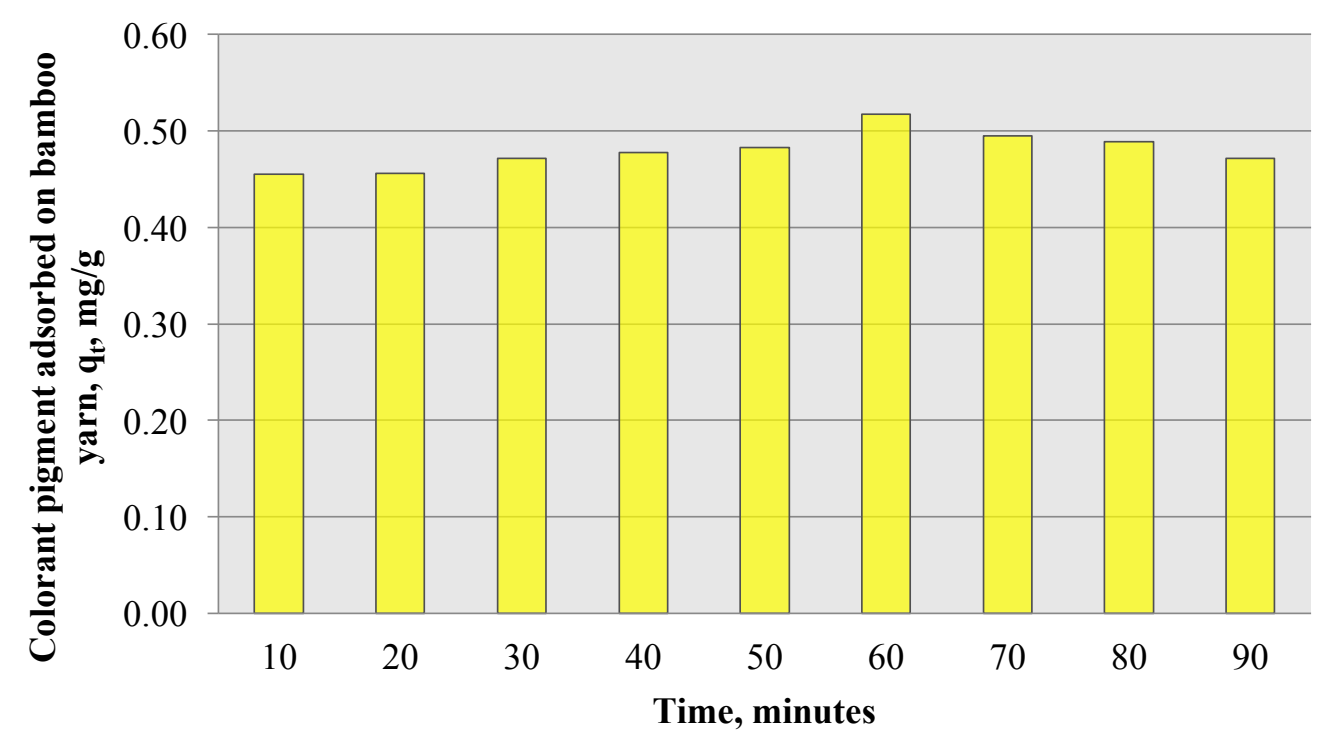

Figure 4 shows the amount of curcumin adsorbed onto bamboo yarn at different time intervals. The equilibrium time was reached at the minute 60 for maximum adsorption curcumin pigment onto bamboo yarn. It confirmed that the strong electrostatic attractive force between the positively charged colorant pigments and the negatively charged bamboo yarn surfaces was the main driving force for adsorption. Moreover, the amount of curcumin adsorbed onto the bamboo yarn increases gradually with increasing contact time until it reaches the maximum amount, which reflects achievement of adsorption equilibrium. At this point, the amount of curcumin pigment adsorbed onto bamboo yarn is in a dynamic equilibrium state. In another word, quick dispersion into the outer surface of the adsorbent happened through a quick pore dissemination into the 
intraparticle lattice, in this manner accomplishing fast balance. As it took 60 minutes to reach equilibrium, the experiment on the adsorption of curcumin onto bamboo yarn at different dilution of factors were also done for 60 minutes.

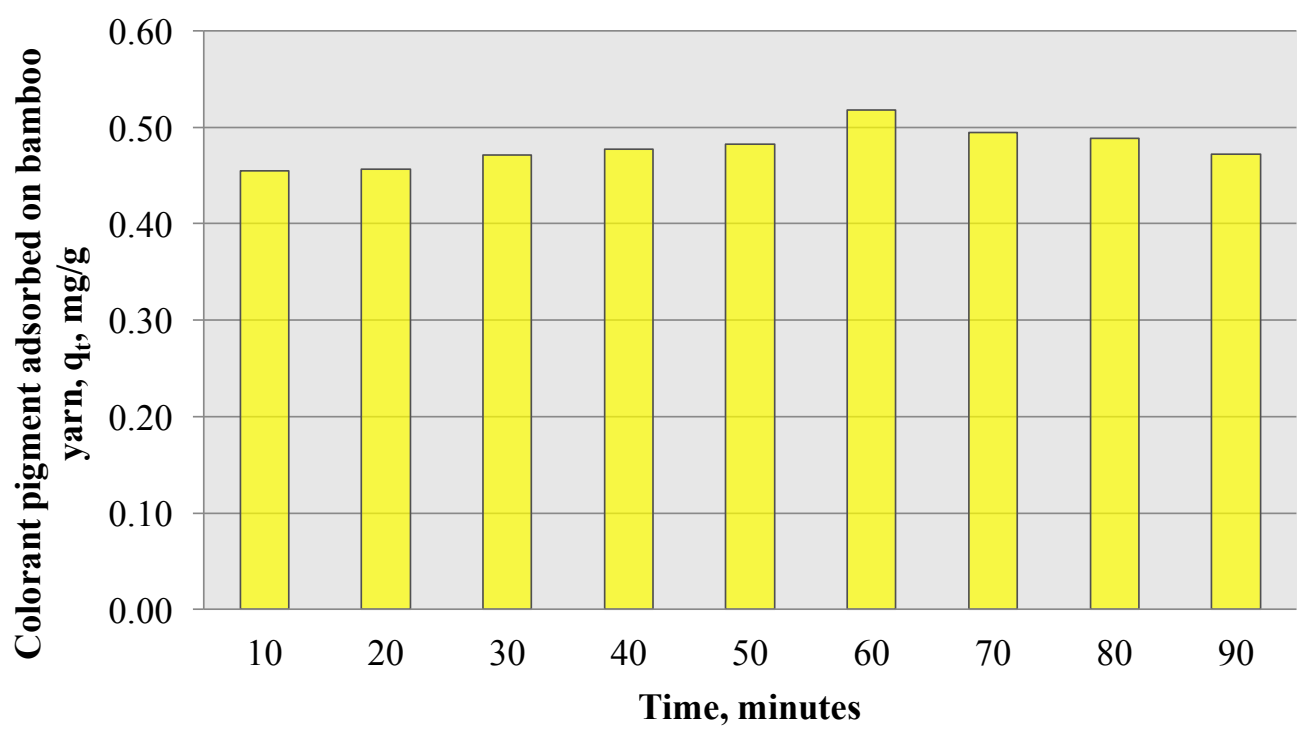

Figure 4: Amount of curcumin adsorbed onto bamboo yarn at different time intervals

\section{Effect of dye bath concentrations on adsorption at equilibrium time}

Figure 5 depicts the amount of dye adsorbed versus dilution factor. The dye bath concentration assumes an imperative part in the adsorption of colorant shades onto bamboo yarn where as higher dilution factor, the lower dye bath concentration. The measure of curcumin adsorbed onto bamboo yarn increments with an expansion in dilution factor. At lower dilution factor, the amount of colorant pigment adsorbed onto bamboo yarn is low. The amount of curcumin extracted from $C$. longa dye that is adsorbed onto bamboo yarn, $\mathrm{q}_{\mathrm{e}}$ in units $\mathrm{mg} / \mathrm{g}$ is increased until it reached the highest point of the dilution factor at 1.25 .

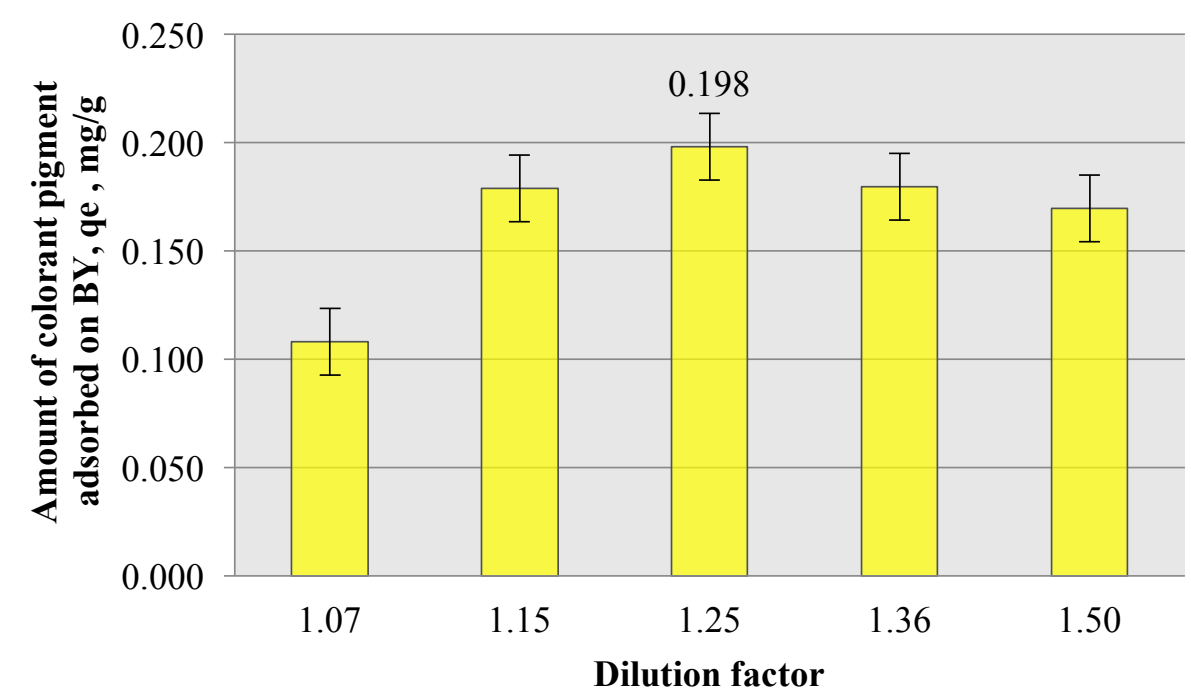

Figure 5: Amount of curcumin adsorbed onto bamboo yarn at equilibrium time and various dilution factors 


\section{Adsorption kinetics}

Pseudo-first request demonstrate accept that the adsorption of colorant shades onto bamboo yarn happens because of a fixation contrast of the adsorbate, between adsorbent surface and the arrangement. In this way, this procedure happens just by the outer mass exchange coefficient (Wei and Brien, 2014). The Lagergen rate condition is the top notch condition for adsorption in a fluid or strong framework in view of strong limit as appeared in equation 4.

$$
\frac{d q_{t}}{d t}=k_{1}\left(q_{e}-q_{t}\right)
$$

After joining on the both sides of the condition and applying conditions for $q \mathrm{t}=0$ at $\mathrm{t}=0$ and $\mathrm{qt}=\mathrm{qt}$ at $\mathrm{t}=\mathrm{t}$, the condition 5 is utilized for the active investigation of trial results.

$$
\log \left(q_{e}-q_{t}\right)=\log q_{e}-\frac{k_{1}}{2.303}
$$

Where the $\mathrm{q}_{\mathrm{e}}$ is the measure of curcumin adsorbed onto bamboo yarn at balance $(\mathrm{mg} / \mathrm{g})$, $\mathrm{q}_{\mathrm{t}}$ is the measure of colorant shades adsorbed onto bamboo yarn at time $\mathrm{t}(\mathrm{mg} / \mathrm{g})$, and $\mathrm{k}_{1}$ is the equilibrium rate consistent of pseudo-first order kinetic $(1 / \mathrm{min})$. The equation plots a straight bend of the $\log \left(\mathrm{q}_{\mathrm{e}}-\mathrm{q}_{\mathrm{t}}\right)$ versus $\mathrm{t}$. The inclines then relate to the estimation of $\mathrm{k}_{1}$. The information are appeared in Figure 6 and evidently, the adsorption of the colorant shades of curcumin onto bamboo yarn does not take after pseudo-first order model. The $\mathrm{k}_{1}$, the ascertained $\mathrm{q}_{\mathrm{e}}\left(\mathrm{q}_{\mathrm{e}, \text { cal }}\right)$ and the coefficient of determination $\left(\mathrm{R}^{2}\right)$ were computed and classified in Table 2.

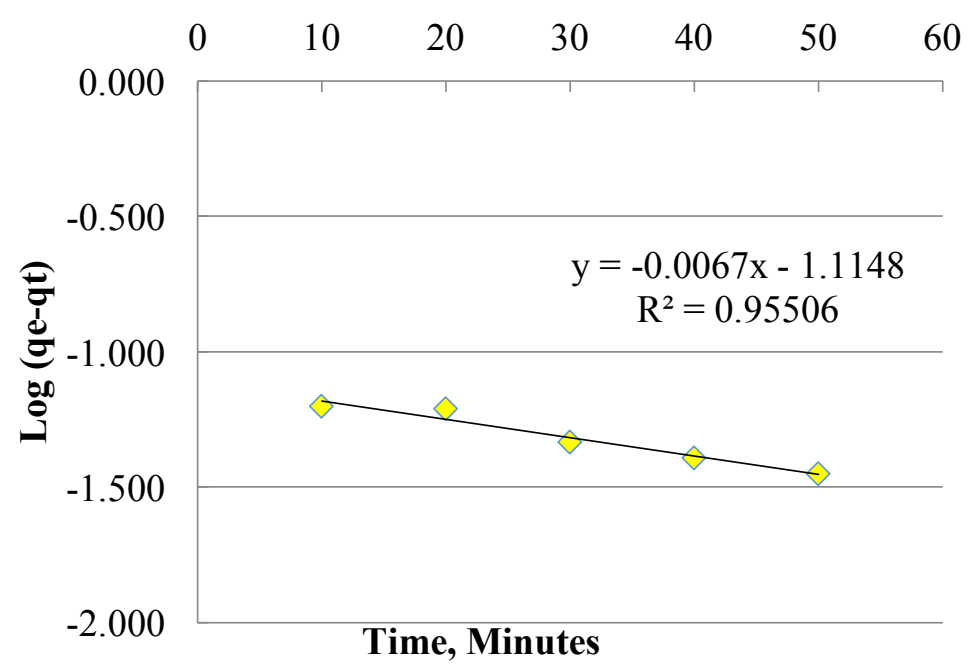

Figure 6: Pseudo-first order kinetic model for curcumin adsorption onto bamboo yarn at $60{ }^{\circ} \mathrm{C}$

Then, the pseudo-second order equation was attempted to fit the adsorption of colorant pigments onto BY data. Following is the pseudo-second order kinetic equation.

$$
\frac{d q_{t}}{d_{t}}=k_{2}\left[\left(q_{e}-q_{t}\right)\right]^{2}
$$


Where $\mathrm{k}_{2}$ is the equilibrium rate constant of pseudo-second order kinetic model $\left(\mathrm{g} \mathrm{mg}^{-}\right.$ $\left.{ }^{1} \mathrm{~min}^{-1}\right)$.Following is the equation obtained by integrating

$$
\frac{1}{q_{t}}=\frac{1}{\left(k_{2} q_{e}^{2}\right)+\left(\frac{1}{q_{e}}\right) t}
$$

Linear plots of $\mathrm{t} / \mathrm{q}_{\mathrm{t}}$ versus $\mathrm{t}$ for the adsorption of the colorant pigments of curcumin onto bamboo yarn was plotted to obtain the rate parameters and shown in Figure 7. This determines the applicability of the model. From this figure, the adsorption of the colorant pigments of curcumin onto bamboo yarn fits the pseudo-second order model. The similar observations were found in the adsorption Adhatoda vasica natural dye onto woollen yarn (Rather et al., 2016). Table 2 displays the $\mathrm{k}_{2}$, the calculated $\mathrm{q}_{\mathrm{e}}\left(\mathrm{q}_{\mathrm{e}, \text { cal }}\right)$ and the coefficient of determination $\left(\mathrm{R}^{2}\right)$.

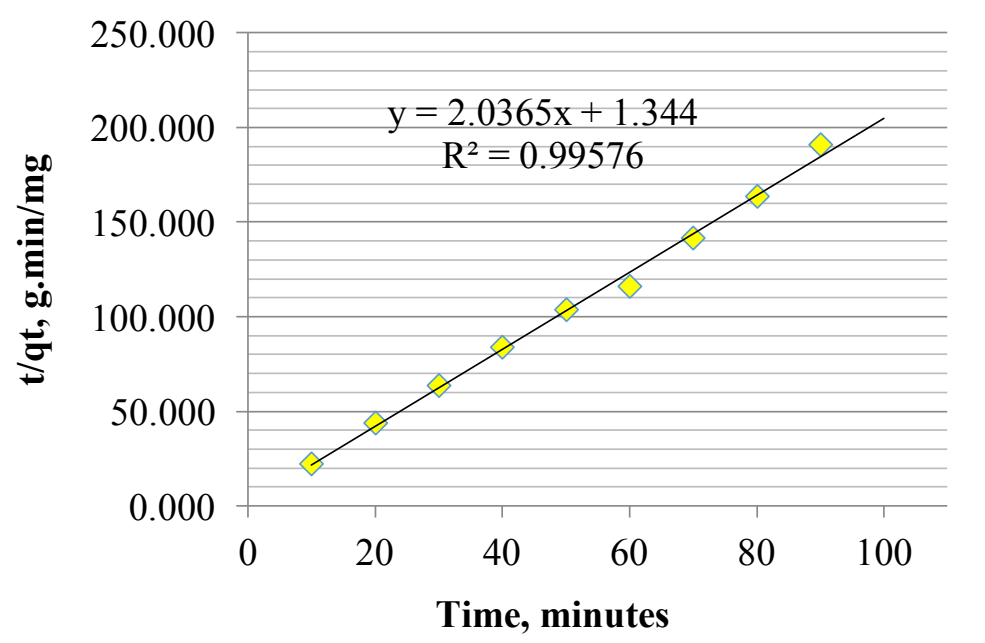

Figure 7: Pseudo-second order kinetic model for curcumin adsorption onto bamboo yarn at $60^{\circ} \mathrm{C}$

From the experimental $\mathrm{q}_{\mathrm{e}}\left(\mathrm{q}_{\mathrm{e}, \exp }\right)$ value obtained agree with the calculated ones $\left(\mathrm{q}_{\mathrm{e}, \mathrm{cal}}\right)$ for adsorption of curcumin pigment. Its show a good linear fit using pseudo-second order kinetic model, as the experimental $\mathrm{q}_{\mathrm{e}}\left(\mathrm{q}_{\mathrm{e}, \exp }\right)$ value obtained agreed with the calculated ones $\left(\mathrm{q}_{\mathrm{e}, \mathrm{cal}}\right)$ of the pseudo-second order kinetic model.Moreover, the coefficient value of determination $\left(\mathrm{R}^{2}\right)$ was 0.995 which is higher than the pseudo-first order kinetic model. On the other hand, a linear fit for $\mathrm{t} / \mathrm{q}_{\mathrm{t}}$ versus $\mathrm{t}$ was observed using pseudo-second order kinetic model. This fitted for the adsorption of the colorant pigments of curcumin onto bamboo yarn where previously similar results on adsorption of cumin dye on silk had been observed (Tayade and Adivarekar, 2013). Therefore, the rate-limiting step may be the chemical adsorption mechanism and dyeing mechanism which is controlled by electrostatic interaction and hydrogen bonding between bamboo yarn surface and colorant pigments molecules of curcumin through the sharing or exchange of electrons between the adsorbent and adsorbate as covalent force and ion exchange. This suggests that curcumin adsorption onto bamboo occur through both of internal and external mass transfer mechanisms and it indicates that the reaction is more inclined towards chemisorption. 
Table 2: Kinetic parameters for curcumin pigments adsorption onto bamboo yarn

\begin{tabular}{ccccccc}
\hline & \multicolumn{3}{c}{ Pseudo first order } & \multicolumn{3}{c}{ Pseudo second order } \\
\cline { 2 - 7 } $\mathrm{q}_{\mathrm{e}, \exp }$ & $\mathrm{q}_{\mathrm{e}, \text { cal }}$ & $\mathrm{k}_{1}$ & $\mathrm{R}^{2}$ & $\mathrm{q}_{\mathrm{e}, \text { cal }}$ & $\mathrm{k}_{2}$ & $\mathrm{R}^{2}$ \\
0.518 & -0.108 & 0.014 & 0.955 & 0.491 & 3.084 & 0.995 \\
\hline
\end{tabular}

Intraparticle diffusion equation was usedto investigate the internal diffusion mechanism during the adsorption of the colorant pigments onto bamboo yarn. Adsorptioninvestigation was according to Weber and Morris model, also known as intraparticle diffusion modelassumes the adsorption mechanism (Benjwal et al., 2016) is controlled by an external film resistance and or mass transfer is controlled by internal or intraparticle diffusion (Wei and Brien, 2014). The possibility of intraparticle diffusion resistance affecting adsorption was explored using equation (8).

$$
q_{t}=k_{p} t^{(1 / 2)}+C
$$

Where $\mathrm{k}_{\mathrm{p}}$ is the intraparticle diffusion rate constant (mg/g.min) and $\mathrm{C}$ is the internal diffusion coefficient, determined from the linear graph of qt versus (time) ${ }^{1 / 2}$ In some cases, three linear sections on a plot of $\mathrm{q}_{\mathrm{t}}$ versus $\mathrm{t}^{1 / 2}$ for curcumin is identifiable. Figure 8 shows the plots for the curcumin adsorption onto bamboo yarn. The plots of $q_{t}$ versus $(\text { time })^{1 / 2}$ indicate multi-linearity. As indicated by the plots, each part speaks to a particular mass exchange instrument. In the colorant shades adsorption on bamboo yarn, an underlying segment in respect to the limit layer dispersion (film dissemination) was observed for 10 to 60 minutes. At that point the mass move venture in colorant shades adsorption onto bamboo yarn was the film dispersion. This may happen because of the closeness of an inflexible and nonporous surface and low estimation of the surface zone of bamboo yarn. Moreover, the colorant shades atomic size might be larger than normal pore span of bamboo yarn, restraining the inside dispersion. The estimations of $\mathrm{C}$ (the point at which the line crosses the y-axis) is 0.606 . As per this model, a plot of take-up is direct, and the adsorption procedure included intraparticle dispersion. The plots don't go through the source where it demonstrates that some level of limit layer control. It additionally demonstrates that the intraparticle dissemination is not by any means the only rate-restricting stride, yet other dynamic models may likewise control the rate of adsorption and all of which might work at the same time.

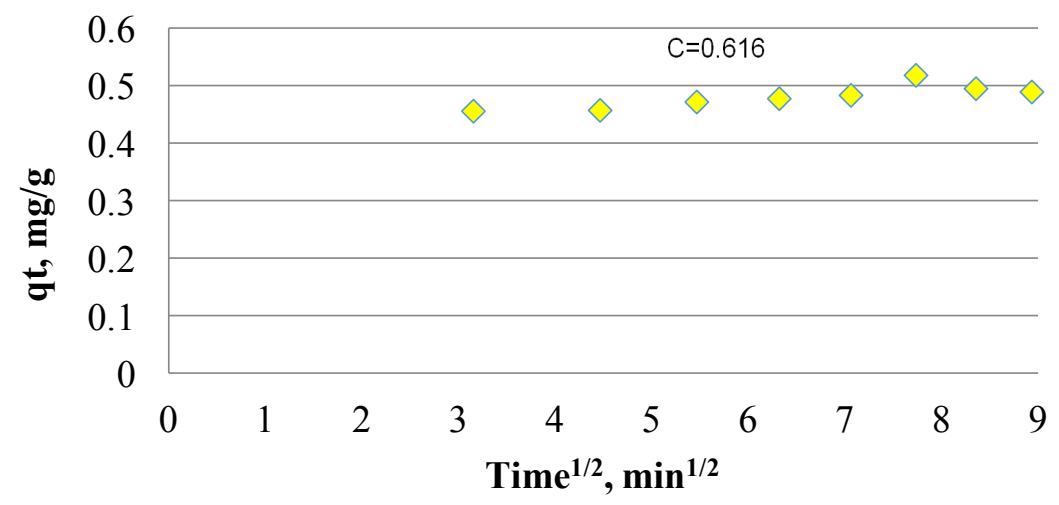

Figure 8: Intraparticle diffusion model for curcumin adsorption onto bamboo yarn 


\section{Adsorption isotherms}

The equilibrium isotherm was important in predictive modelling for analysis and design of adsorption systems for bamboo yarn. So, the equilibrium adsorption data fits Langmuir, Freundlich, Temkin and Dubini-Radushkevish isotherm models. The linear expression of Langmuir isotherm is as follows:

$$
\frac{1}{q_{e}}=\frac{1}{q_{\max }}+\frac{1}{q_{\max } K_{L} C_{e}}
$$

Where $q_{e}$ and $C_{e}$ are the amount of dye adsorbed per gram of bamboo yarn $(\mathrm{mg} / \mathrm{g})$ and dye concentration $(\mathrm{mg} / \mathrm{mL})$ in the dye bath at equilibrium, respectively. $q_{\max }(\mathrm{mg} / \mathrm{g}$ bamboo yarn) is the maximum dye adsorbed per unit weight of bamboo yarn for complete monolayer adsorption. $K_{L}$ is Langmuir constant related to affinity of binding sites $(\mathrm{mL} / \mathrm{mg})$. Further, description of Langmuir isotherm can be expressed in terms of the dimensionless constant separation factor for equilibrium parameter, $\mathrm{R}_{\mathrm{L}}$ (Shabbir et al. 2016), defined as follows:

$$
R_{L}=\frac{1}{1+K_{L} C_{0}}
$$

Freundlich isotherm is also an adsorption isotherm, in which there is a curve relating the concentration of a solute on the surface of adsorbent to the concentration of solute which is present in the liquid in which it is in contact. The equation is as below:

$$
\log q_{e}=\log K_{f}+\frac{1}{n} \log C_{e}
$$

$K_{f}$ is the Freundlich adsorption constant and $n$ is that of the adsorption intensity. $K_{f}$ and $n$ can be determined from slope and intercept of linear plot $\log q_{e}$ versus $\log C_{e}$. The value of $n>1$ represents favorable adsorption. This isotherm contains a factor that explicitly taking into the account of adsorbent-adsorbate interactions. By ignoring the extremely low and large value of concentrations, the model assumes that heat of adsorption (function of temperature) of all molecules in the layer would decrease linearly rather than logarithmic with coverage (Dada et al., 2012). The linear form of Temkin isotherm equation is represented as:

$$
\begin{aligned}
& q_{e}=\frac{R T}{b_{T}} \ln A_{T}+\frac{R T}{b_{T}} \ln C_{e} \\
& B=\frac{R T}{b_{T}}
\end{aligned}
$$

$K_{T}(\mathrm{~L} / \mathrm{mg})$ is the equilibrium binding constant of Temkin isotherm model corresponding to the maximum binding energy. Constant $B_{1}$ is related to the heat of adsorption. $R T$ was associated to the adsorption heat. $A_{T}$ was the equilibrium constant corresponding to the maximum bind energy. Dubinin-Radushkevich isotherm is generally applied to express the adsorption mechanism with a Gaussian energy distribution onto a heterogeneous surface (Dada et al., 2012). The model has often successfully fitted high solute activities and the intermediate range of concentrations data well. This isotherm is used to determine whether the adsorption is chemical or physical in nature (Wei \& Brien, 2014). Linear form of Dubinin-Radushkevich equation is given below: 


$$
\ln q_{e}=\ln q_{D}-\beta_{D} \varepsilon^{2}
$$

Where $\mathrm{q}_{\mathrm{e}}$ is the adsorption capacity at equilibrium (mol $\left./ \mathrm{g}\right), q_{D}$ is DubininRadushkevich monolayer saturation capacity $(\mathrm{mol} / \mathrm{g}), \beta_{\mathrm{D}}$ is constant related to the mean free energy of adsorption per mole of the adsorbate $\left(\mathrm{mol}^{2} / \mathrm{J}^{2}\right)$ and $\varepsilon^{2}$ is the Polanyi potential which is related to the equilibrium concentration $\left(\mathrm{J}^{2} / \mathrm{mol}^{2}\right)$.

$$
\begin{aligned}
& \varepsilon=R T \ln \left(1+1 / C_{e}\right) \\
& E_{D R}=\frac{1}{\sqrt{\left(2 \beta_{D}\right)}}
\end{aligned}
$$

$\mathrm{R}$ is the gas constant $(8.314 \mathrm{~J} / \mathrm{mol} . \mathrm{K}), \mathrm{T}$ is absolute temperature $(\mathrm{K})$, and $\mathrm{Ce}$ is the equilibrium dye concentration. $E_{D R}$ parameter is helpful for assessing the sort of adsorption connection. In the event that the adsorption procedure is fundamentally physical in nature, for example, Van der Waals powers, the normal free vitality is ordinarily in the scope of $1-8 \mathrm{~kJ} / \mathrm{mol}$. In the event that $\mathrm{E}_{\mathrm{DR}}$ is between $8-16 \mathrm{~kJ} / \mathrm{mol}$, the adsorption procedure is chemisorption by means of particle trade. To find the most appropriate model to describe the adsorption behaviours of $C$. longa dye onto bamboo yarn, all the isotherms were fitted by using linear least-squares fitting procedure. By comparing correlation coefficients, $\mathrm{R}^{2}$ of all isotherm models presented in Table 3 , it is concluded that Freundlich (Error! Reference source not found.) gave the best fit to experimental data of adsorption isotherm of $C$. longa dye onto bamboo yarn compared Langmuir (Figure 9(a)), Temkin (Figure ) and Dubinin-Radushkevich (Error! Reference source not found.) isotherm models. $R_{L}$ for curcumin was observed within 1 and $0(0.997)$ which indicating the adsorption is favourable. The magnitude of the exponent $1 / \mathrm{n}$ gives an indication of the favorability of adsorption. The value of $n>1$ represents favorable adsorption(Shabbir et al. 2016). In this research, the value of $n$ was observed was more that 1(1.233) which indicating favourable. For curcumin adsorption onto bamboo yarn tested, the mean free energy of adsorption calculated for the interaction is $15.81 \mathrm{~kJ} / \mathrm{mol}$. The EDR of fall within the range of is between $8-16 \mathrm{~kJ} / \mathrm{mol}$ indicate that the adsorption is chemical adsorption and the electrostatic fascination between emphatically charged bamboo yarn and contrarily charged of curcumin. This conceivable nature of adsorption was likewise demonstrated by the pseudo-second order kinetic model for adsorption of curcumin.

Table 3: Kinetic parameters for the adsorption of Curcuma longa L.,dye onto yarn

\begin{tabular}{|c|c|c|c|c|}
\hline \multirow{2}{*}{ Langmuir } & $\mathbf{R}^{\mathbf{2}}$ & $\begin{array}{c}\mathbf{q} \mathbf{m a x} \\
(\mathbf{m g} / \mathbf{g})\end{array}$ & $\begin{array}{c}\mathbf{K}_{\mathbf{L}} \\
(\mathbf{L} / \mathbf{m g})\end{array}$ & $\mathbf{R}_{\mathbf{L}}$ \\
\cline { 2 - 5 } & 0.671 & 0.038 & 0.084 & 0.997 \\
\hline \multirow{2}{*}{ Freundlich } & $\mathbf{R}^{\mathbf{2}}$ & $\mathbf{n}$ & $\mathbf{K}_{\mathbf{F}}(\mathbf{L} / \mathbf{g})$ & \\
\cline { 2 - 5 } Temkin & 0.975 & 1.233 & -0.418 & $\mathbf{B}$ \\
\hline \multirow{2}{*}{$\begin{array}{c}\text { Dubinin- } \\
\text { Radushkevish }\end{array}$} & $\mathbf{R}^{2}$ & $\begin{array}{c}\mathbf{A}_{\mathbf{T}} \\
(\mathbf{L} / \mathbf{m g})\end{array}$ & $\begin{array}{c}\mathbf{b}_{\mathbf{T}} \\
(\mathbf{K J} / \mathbf{m o l})\end{array}$ \\
\cline { 2 - 5 } & 0.852 & -0.219 & 2.999 & 3.491 \\
\cline { 2 - 5 } & 0.750 & $\begin{array}{c}\mathbf{q}_{\mathbf{D}} \\
(\mathbf{m o l} / \mathbf{g})\end{array}$ & $\begin{array}{c}\boldsymbol{\beta}_{\mathbf{D}} \\
\left(\mathbf{m o l}^{\mathbf{2}} / \mathbf{J}^{\mathbf{2}}\right)\end{array}$ & $\begin{array}{c}\mathbf{E}_{\mathbf{D R}} \\
(\mathbf{k J} / \mathbf{m o l})\end{array}$ \\
\hline
\end{tabular}


(a)

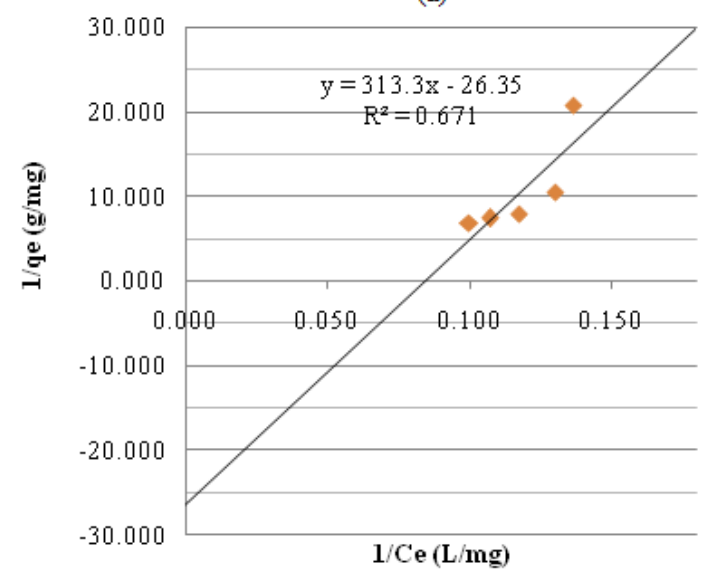

(b)

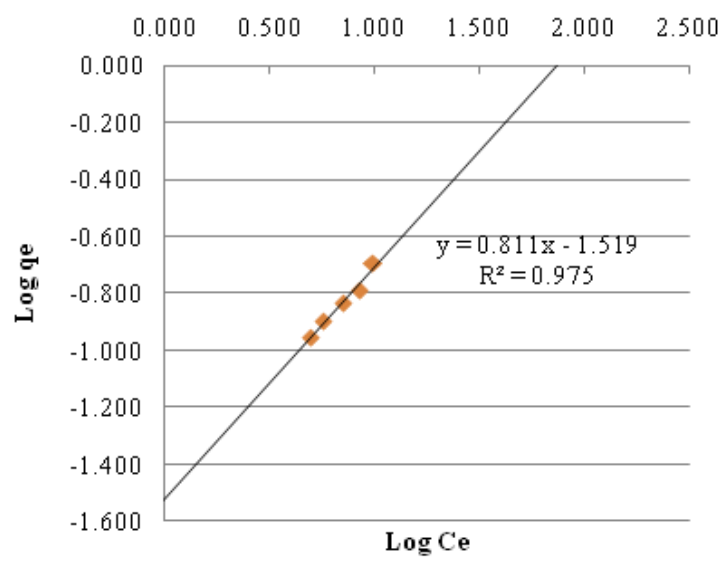

Figure 9: (a) Langmuir isotherm of adsorption of Curcuma longa L.,dye onto bamboo yarn and (b) Freundlich isotherm of adsorption of Curcuma longa L.,dye onto bamboo yarn

(a)

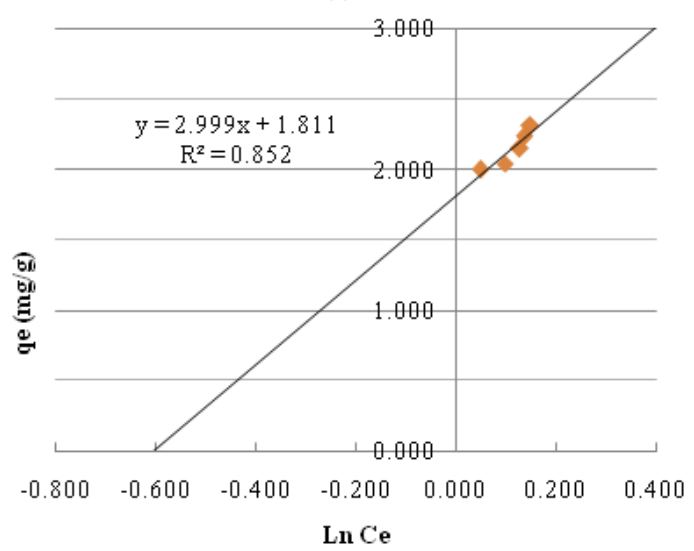

(b)

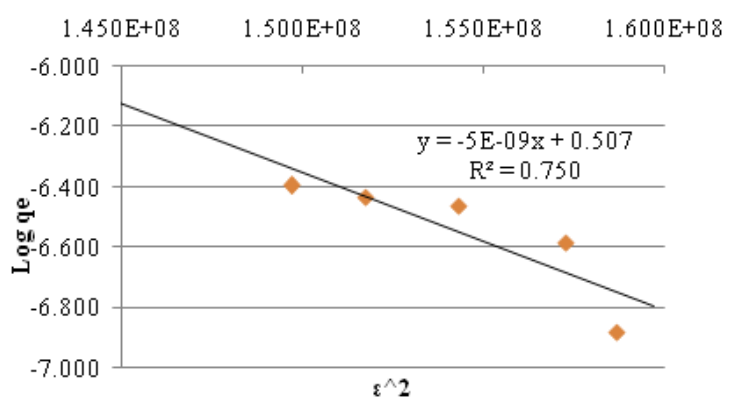

Figure 10: (a) Temkin isotherm of adsorption of Curcuma longa L.,dye onto bamboo yarn and (b) Dubinin-Radushkevich isotherm of adsorption of Curcuma longa L.,dye onto bamboo yarn

\subsection{CONCLUSION}

The major coloring component obtained from the rhizome of $C$. longa dye is curcumin. The adsorption isotherm of curcumin on bamboo yarn was carried out using different models: Langmuir, Freundlich, Tempkin and Dubinin-Radushkevich models. The adsorption of curcumin on bamboo yarn fitted well to the Freundlich isotherm. The kinetic study proved that the adsorption of curcumin onto bamboo yarn fitted to pseudosecond order kinetic model which indicating the interaction by chemical adsorption. The adsorption of $C$. longa dye on bamboo yarn has been demonstrated in this research. However, futher studies considering alternative curcumin sources, optimization of color retention, interactions with other types of fabric/yarn are still required. 


\section{REFERENCES}

Anusuya, S. \& Sathiyabama, M., 2016. Effect of chitosan on growth, yield and curcumin content in turmeric under field condition. Biocatalysis and Agricultural Biotechnology, 6, pp.102-106.

B, D.L.R. \& Ravi, D., 2013. Extraction of Natural Dyes From Selected Plant Sources and Its Application in Fabrics. International Journal of Textile and Fashion Technology, 3(2), pp.53-60.

Benjwal, P., Sharma, R. \& Kar, K.K., 2016. Effects of surface microstructure and chemical state of feather fiber-derived multidoped carbon fibers on the adsorption of organic water pollutants. Materials \& Design, 110, pp.762-774.

Boonsong, P., Laohakunjit, N. \& Kerdchoechuen, O., 2012. Natural pigments from six species of Thai plants extracted by water for hair dyeing product application. Journal of Cleaner Production, 37, pp.93-106.

$\mathrm{Bu}$, R. et al., 2016. Adsorption capability for anionic dyes on 2-hydroxyethylammonium acetateintercalated layered double hydroxide. Colloids and Surfaces A: Physicochemical and Engineering Aspects, 511, pp.312-319.

Chen, H., 2014. Biotechnology of lignocellulose: Theory and practice,

Dada, A.. et al., 2012. Langmuir, Freundlich, Temkin and Dubinin - Radushkevich Isotherms Studies of Equilibrium Sorption of $\mathrm{Zn} 2+$ Unto Phosphoric Acid Modified Rice Husk. IOSR Journal of Applied Chemistry, 3(1), pp.38-45.

Haddar, W., Ben Ticha, M., et al., 2014. A novel approach for a natural dyeing process of cotton fabric with Hibiscus mutabilis (Gulzuba): process development and optimization using statistical analysis. Journal of Cleaner Production, 68, pp.114-120.

Haddar, W., Elksibi, I., et al., 2014. Valorization of the leaves of fennel (Foeniculum vulgare) as natural dyes fixed on modified cotton: A dyeing process optimization based on a response surface methodology. Industrial Crops and Products, 52, pp.588-596. Available at: http://dx.doi.org/10.1016/j.indcrop.2013.11.019.

Hmar, B.Z., Kalita, D. \& Srivastava, B., 2016. Optimization of microwave power and curing time of turmeric rhizome (Curcuma Longa L.) based on textural degradation. LWT - Food Science and Technology.

Khan, A.A. et al., 2014. Extraction of natural dye from red calico leaves: Gamma ray assisted improvements in colour strength and fastness properties. Dyes and Pigments, 103, pp.50-54. Available at: http://linkinghub.elsevier.com/retrieve/pii/S0143720813004683.

Kulkarni S. S., Bodake U. M., P.G.R., 2011. Extraction of Natural Dye from Chili ( Capsicum Annum ) for Textile Coloration., 1, pp.58-63.

Nasirizadeh, N. et al., 2012. Optimization of wool dyeing with rutin as natural dye by central composite design method. Industrial Crops and Products, 40, pp.361-366.

Osorio-Tobón, J.F. et al., 2016. Fast analysis of curcuminoids from turmeric (Curcuma longa L.) by highperformance liquid chromatography using a fused-core column. Food Chemistry, 200, pp.167-174.

Prakash, C., Ramakrishnan, G. \& Koushik, C.V., 2012. A study of the thermal properties of single jersey fabrics of cotton, bamboo and cotton/bamboo blended-yarn vis-a-vis bamboo fibre presence and yarn count. Journal of Thermal Analysis and Calorimetry, 110(3), pp.1173-1177.

Rather, L.J. et al., 2016. Adsorption and Kinetic studies of Adhatoda vasica natural dye onto woolen yarn with evaluations of Colorimetric and Fluorescence Characteristics. Journal of Environmental Chemical Engineering, 4(2), pp.1780-1796.

Sachan, K. \& Kapoor, V., 2007. Optimization of extraction and dyeing conditions for traditional turmeric dye. Indian Journal of Traditional Knowledge, 6(April), pp.270-278. Available at: http://nopr.niscair.res.in/handle/123456789/918.

Sathiyabama, M., Bernstein, N. \& Anusuya, S., 2016. Chitosan elicitation for increased curcumin production and stimulation of defence response in turmeric (Curcuma longa L.). Industrial Crops and Products, 89, pp.87-94.

Selvam, R.M. et al., 2015. Extraction of natural dyes from Curcuma longa, Trigonella foenum graecum and Nerium oleander, plants and their application in antimicrobial fabric. Industrial Crops and Products, 70, pp.84-90. Available at: http://dx.doi.org/10.1016/j.indcrop.2015.03.008.

Shabbir, M. et al., 2016. An eco-friendly dyeing of woolen yarn by Terminalia chebula extract with evaluations of kinetic and adsorption characteristics. Journal of Advanced Research, 7(3), pp.473482.

Shams-Nateri, A., 2011. Reusing wastewater of madder natural dye for wool dyeing. Journal of Cleaner Production, 19(6), pp.775-781.

Sinha, K., Saha, P. Das \& Datta, S., 2012. Extraction of natural dye from petals of Flame of forest (Butea monosperma) flower: Process optimization using response surface methodology (RSM). Dyes and 
Pigments, 94(2), pp.212-216. Available at: http://dx.doi.org/10.1016/j.dyepig.2012.01.008.

Sivakumar, V. et al., 2009. Ultrasound assisted enhancement in natural dye extraction from beetroot for industrial applications and natural dyeing of leather. Ultrasonics Sonochemistry, 16(6), pp.782-789.

Tausif, M. et al., 2015. A comparative study of mechanical and comfort properties of bamboo viscose as an eco-friendly alternative to conventional cotton fibre in polyester blended knitted fabrics. Journal of Cleaner Production, 89, pp.110-115.

Tayade, P.B. \& Adivarekar, R. V., 2013. Adsorption kinetics and thermodynamic study of Cuminum cyminum L. dyeing on silk. Journal of Environmental Chemical Engineering, 1(4), pp.1336-1340.

Wei, C. \& Brien, L.O., 2014. Removal of Acid Yellow 25 Dye onto Chitin Extracted from Waste Crab legs and Study of Adsorption Isotherms and Kinetics of AY25 Dye Adsorption, Southern Illinois University Edwardsville.

Zhou, Y. et al., 2015. Simultaneous dyeing and functionalization of silk with three natural yellow dyes. Industrial Crops and Products, 64, pp.224-232. 